\title{
The role of physical activity in rheumatoid arthritis
}

Citation for published version (APA):

Plasqui, G. (2008). The role of physical activity in rheumatoid arthritis. Physiology \& Behavior, 94(2), 2705. https://doi.org/10.1016/j.physbeh.2007.12.012

Document status and date:

Published: 01/01/2008

DOI:

10.1016/j.physbeh.2007.12.012

Document Version:

Publisher's PDF, also known as Version of record

Document license:

Taverne

\section{Please check the document version of this publication:}

- A submitted manuscript is the version of the article upon submission and before peer-review. There can be important differences between the submitted version and the official published version of record.

People interested in the research are advised to contact the author for the final version of the publication, or visit the DOI to the publisher's website.

- The final author version and the galley proof are versions of the publication after peer review.

- The final published version features the final layout of the paper including the volume, issue and page numbers.

Link to publication

\footnotetext{
General rights rights.

- You may freely distribute the URL identifying the publication in the public portal. please follow below link for the End User Agreement:

www.umlib.nl/taverne-license

Take down policy

If you believe that this document breaches copyright please contact us at:

repository@maastrichtuniversity.nl

providing details and we will investigate your claim.
}

Copyright and moral rights for the publications made accessible in the public portal are retained by the authors and/or other copyright owners and it is a condition of accessing publications that users recognise and abide by the legal requirements associated with these

- Users may download and print one copy of any publication from the public portal for the purpose of private study or research.

- You may not further distribute the material or use it for any profit-making activity or commercial gain

If the publication is distributed under the terms of Article $25 \mathrm{fa}$ of the Dutch Copyright Act, indicated by the "Taverne" license above, 


\title{
The role of physical activity in rheumatoid arthritis
}

\author{
Guy Plasqui* \\ Department of Human Biology, Maastricht University, PO Box 616, 6200 MD Maastricht, The Netherlands
}

Received 29 August 2007; received in revised form 18 December 2007; accepted 18 December 2007

\begin{abstract}
Rheumatoid arthritis (RA) is a chronic inflammatory auto-immune disease, causing progressive damage to the musculoskeletal system. Many patients with RA also suffer from accelerated muscle loss or cachexia, which contributes to the loss of physical function and quality of life. Physical activity plays a central role in the management of the disease as it is essential to maintain muscle strength and endurance, range of motion and the ability to perform activities of daily life. On the other hand, given the nature of the disease, there is always an increased risk for injury. There is a large amount of literature investigating the effect of exercise interventions on muscle function and disease activity. These studies show that exercise clearly improves muscle function without affecting disease activity. Studies including radiographic evaluation of joint damage as an endpoint also show that there is no evidence that exercise, even high-intensity exercise, increases inflammation or joint damage, although care should be taken with patients with severe baseline damage. Regarding daily physical activity (exercise is only one component of physical activity) there is hardly any research done showing either that physical activity is indeed decreased in patients or whether or not there is a relation between daily physical activity and disease activity. The results from studies looking at the effect of exercise on muscle mass or the ability to prevent or reverse cachexia are somewhat contradictory, but it seems that when the training dose is sufficiently large, gains in muscle mass can be achieved. (C) 2008 Elsevier Inc. All rights reserved.
\end{abstract}

Keywords: Physical activity; Exercise; Rheumatoid cachexia; Disease activity

\section{Introduction}

Rheumatoid arthritis (RA) is an inflammatory auto-immune disease affecting primarily the synovium. It is characterised by chronic, symmetric polyarthritits and erosive synovitis, which may lead to several degrees of articular destruction, loss of function and increased energy expenditure [1]. Systemic complaints such as fatigue and weight loss are not infrequent. It affects approximately $1 \%$ of the adult population, and is most prevalent among those aged $40-60$ years. The risk of developing rheumatoid arthritis is about five times higher in women [2]. As a consequence of their disease, patients suffer from joint pain, restricted mobility and reduced muscle strength and endurance [3]. It has been reported that 10 years after disease onset, $32.7 \%$ of patients had stopped working for health reasons [4]. Since it concerns a musculoskeletal disorder, it was initially thought that

\footnotetext{
* Tel.: +31 43388 1506; fax: +31 433670976.

E-mail address: G.Plasqui@HB.Unimaas.NL.
}

exercise, putting extra strain on the joints, might worsen the symptoms and cause additional joint damage. The advice against exercise resulted from the presumption that more weight-bearing gives more damage to the inflamed and already damaged joints and that the inflammation could be perpetuated by moving the joint. Furthermore, since RA patients have a fear of moving there was a strong disbelief that patients were able and willing to exercise. However, as will become clear in this review, exercise or physical activity in general, plays an essential role in the management of the disease.

In addition to the pathophysiology described above, many patients suffering from RA also suffer from an accelerated loss of muscle mass, also known as rheumatoid cachexia, which is thought to contribute to a $2-5$ times higher all-cause mortality and reduced life-expectancy of 3-18 years [5]. As will be explained later, physical activity is likely to play a central role in the pathogenesis of rheumatoid cachexia.

This review will discuss the importance of physical activity in the management of RA from several points of view. A differentiation will be made between exercise per se and physical activity 
in general. The effect of exercise on the progression of the disease, either positively or negatively, will be discussed, as well as the effect on the major symptoms such as joint pain, restricted mobility and fatigue, on muscle strength and endurance, and quality of life in general. In addition, the role of physical activity in the prevention or treatment of cachexia will be addressed. For some of these topics, a large amount of literature is available, and the discussion here will be based on bringing together the results from other excellent systematic reviews. For other topics, literature is more scarce, allowing a more detailed description of the original articles.

\section{Exercise, physical activity and activity related energy expenditure}

Before one can discuss the role of physical activity in the context of RA, it should be pointed out that although exercise, physical activity and activity related energy expenditure are clearly related, they are not the same.

Physical activity in the broadest context includes all body movements, produced by skeletal muscles, that result in energy expenditure [6]. It is a complex behaviour including sports as well as non-sports activities. Sports are often planned, structured and repetitive with the objective to improve or maintain physical fitness [6] while non-sports activities can be subdivided into different categories such as occupational, leisure time and household activities, personal care or transportation. With regards to sports or exercise, a distinction can be made between aerobic (endurance) training and strength (resistance) training. The differentiation between exercise and physical activity might seem obvious, but these terms are often used interchangeably, while in fact exercise is only one aspect of physical activity. The relevance of this differentiation can be nicely illustrated with a study of Meijer et al. [7]. It was shown that in an elderly population $(>55 \mathrm{y})$, exercise training did not result in an increase of total daily physical activity. In fact, exercise training was compensated for by a significant decrease in non-training physical activity.

Total energy expenditure (TEE) consists of basal metabolic rate (BMR), diet induced thermogenesis (DIT) and activity related energy expenditure (AEE). Although BMR is about two thirds and hence the largest component of TEE in moderately active subjects, AEE is the most variable component and the easiest to manipulate. As is clear from the definition, physical activity always results in energy expenditure. But, when using activity related energy expenditure as a quantity of physical activity, it should be realised that the amount of energy expenditure is not just determined by the amount of body movement. In fact, the main determinant of energy expenditure is body mass or more specifically body composition. Furthermore, chronic inflammation is known to increase energy expenditure as well. Indeed, it has repeatedly been shown that BMR is increased in patients with RA [8,9]. In addition, De Carvalho et al. showed that during standardises walking on a treadmill, oxygen consumption and hence energy expenditure was significantly higher in patients with RA than healthy controls, as was the rate of perceived exertion [1]. This implies that the metabolic cost of daily physical activities like walking, cycling or household activities might be higher in patients. It is plausible that this contributes to increased fatigue.

So basically, an exercise intervention does not necessarily mean an increase in daily physical activity and an equal activity related energy expenditure between groups does not necessarily mean an equal amount of physical activity but might merely reflect differences in body size, composition or disease activity.

\section{Is habitual physical activity reduced in patients with RA?}

It is generally assumed that habitual physical activity is decreased in patients with RA as a consequence of joint pain, restricted mobility, fatigue, reduced muscle mass, strength and endurance. However, there is surprisingly little research available comparing daily life physical activity between patients with RA and healthy controls. Self-reported physical activity using the Paffenbarger Physical Activity and Exercise Index showed that patients spent significantly less kcal on physical activity compared to controls which was mainly caused by less walking [10]. Another study showed that patients with newly diagnosed RA performed less leisure activities as assessed by a leisure activity scale [11]. Lemmey et al. showed significantly lower levels of physical activity in patients with RA versus controls using a questionnaire that quantifies physical activity undertaken during a normal week on an 8 point scale [12]. In contrast, data collected from the Nurses Health Study showed no significant difference in questionnaire assessed physical activity between women with and without RA [13]. Studies using objective methods to assess physical activity are even more scarce. Roubenoff et al. used both accelerometry and doubly labelled water (the golden standard to assess total daily energy expenditure) to assess daily physical activity in 20 women with RA and 20 healthy controls matched for age and body mass index (BMI). The physical activity level (PAL), calculated as total energy expenditure divided by resting, was lower in patients than in controls $(1.70 \pm 0.24$ versus $1.89 \pm 0.35 ; p=0.07)$ which was confirmed by significantly less energy spent on physical activity as measured by the Caltrac accelerometer [14]. However, the reported PAL for patients in this study (1.70) is the same as the average PAL for the normal female population (1.69 \pm 0.23 ) of the same age as found by a meta-analysis of 574 doubly labelled water studies [15]. So it seems that the control population had a high PAL compared to the general population rather than the PAL in patients to be lower. Another study using two different motion sensors (Caltrac accelerometer and the University of Cincinnati Motion Sensor) found a trend for a decreased daily physical activity in children with juvenile rheumatoid arthritis as compared to healthy children although the difference was not significant ( $p=0.07$ for both accelerometers) [16]. In the same study, the results from a 3-day activity record and a questionnaire showed significantly lower levels of physical activity in patients and less participation in strenuous activities.

Although this literature provides some support for the notion that physical activity is indeed decreased in patients with RA, there is clearly a lack of hard evidence-based on objective assessment methods. 


\section{Exercise in the treatment of RA}

In contrast to the literature on habitual physical activity, a lot more research focussed on the effect of exercise training on different disease parameters. Given the nature of the disease, i.e. a musculoskeletal disorder, the question arises whether exercise, putting extra strain on the joints, is beneficial or aggravates disease activity. Basically the questions to be answered are 1) what is the effect of exercise on muscle strength and endurance, fatigue, physical functioning and hence quality of life and 2) does exercise affect joint damage?

Historically, the goals of exercise were directed at pain relief and improvement of joint mobility and flexibility. In the last decades, exercise has increasingly been directed towards improvement of muscle strength and aerobic capacity with the ultimate goal to improve functional ability and quality of life. A reduced function will result in decreased ability to perform activities of daily life, decreased independence and the adoption of a sedentary lifestyle with a negative psychosocial impact and an increased risk for cardiovascular disease. With respect to the musculoskeletal system, the three most essential elements for optimal functioning are range of motion (flexibility), strength and aerobic capacity (endurance). Most exercise intervention trials are based on resistance and/or aerobic training.

A large number of trials have been published with respect to the effect of exercise training on disease progress, pain, quality of life, range of motion, strength and aerobic fitness. Studies differ with respect to the specifics of the exercise regimen (type, duration and frequency), the types of patients included, and the end points used. Stenström and Minor concluded from 15 randomised controlled trials that there is a growing body of evidence that aerobic or strengthening exercise has beneficial effects on aerobic capacity and muscle function respectively. Most studies however found no effect on pain, range of motion, the ability to perform activities of daily life or health-related quality of life. There was also no evidence of a positive or negative effect on disease activity or joint destruction [17]. Recently, the evidence with regards to the role of therapeutic exercise in the management of RA in adults was reviewed by an expert panel [2]. Ninety relevant publications were identified of which 16 met the selection criteria and were included in the analysis. The Panel concluded that there was sufficient evidence to support the use of therapeutic exercises, especially knee functional strengthening, general physical activity, and whole-body, low intensity exercises for the management of RA. Conversely, evidence was lacking at present as to whether the use of shoulder and hand strengthening exercises and whole-body, highintensity exercises should be included or excluded in the daily practice of physical rehabilitation for RA management [2]. Another recent review by Pedersen and Saltin [18] assessed the positive effect of training on pathogenesis, symptoms specific to RA, physical fitness or strength, and quality of life and rated the available evidence as strong, moderate, limited or no evidence. They concluded that there was considerable agreement between the studies that dynamic physical activity improves physical fitness and muscle strength, but has no or only a moderate effect on disease activity and pain.

\section{Exercise and rheumatoid cachexia}

Patients with RA have restricted mobility, reduced muscle strength, ranging from 30 to $70 \%$ of that seen in people of similar age, and reduced endurance, typically $50 \%$ of healthy controls $[3,18,19]$. Reduced habitual physical activity may be caused by joint pain, restricted mobility and fatigue, and will result in decreased physical fitness. Since total body cell mass (also referred to as lean body mass or fat-free mass) is the main determinant of functional capacity, the lower body cell mass observed in cachectic patients might be both a consequence and a cause of lower physical activity. Furthermore, the metabolic cost of performing a specific activity, as mentioned above, might be higher in patients compared to healthy subjects [1], and may be an additional cause of decreased physical activity. The end result is a vicious circle, where inflammation leads to pain, joint destruction and muscle wasting resulting in decreased physical activity and physical fitness. Decreased physical fitness will lead to a lower functional capacity which, in turn, could decrease physical activity and fitness even further [20].

In the long term, this cascade of events has consequences for morbidity and mortality. The result of the loss of body cell mass and decreased physical activity is an unfavourable body composition. As compared to healthy controls, many patients have a lower fat-free mass and a relatively high fat mass, while body mass often remains unchanged $[8,21]$. This is also referred to as cachectic obesity, and in the long term may lead to a higher risk for insulin resistance and cardiovascular disease.

Cachexia is characterised by a cytokine driven accelerated loss of muscle mass. Tumour necrosis factor (TNF)- $\alpha$ is a proinflammatory cytokine, mainly produced by macrophages and activated lymphocytes but also muscle cells, and its production increases in response to inflammation. TNF plays a central role in the pathogenesis of inflammatory rheumatic diseases such as RA and ankylosing spondylitis $[22,23]$. Anti TNF- $\alpha$ is a novel and frequently used treatment option in patients with active RA and ankylosing spondylitis. Days to weeks after starting the treatment, it improves the inflammation and thereby the functional ability and it retards the progression of radiological joint damage. TNF- $\alpha$ has also been shown to be a key player in the pathogenesis of accelerated muscle loss [24]. Although the exact underlying pathophysiologic mechanism remains unclear, it is known that TNF- $\alpha$ can induce muscle loss directly by both stimulating muscle protein breakdown and reducing the sensitivity of skeletal muscle cells to anabolic stimuli [25]. One possible pathway is that TNF- $\alpha$ activates nuclear factor (NF)- $\mathrm{kB}$ which in turn suppresses MyoD, a transcription factor that regulates muscle cell differentiation [24]. In addition to the direct effects of TNF- $\alpha$ on muscle anabolism and catabolism, TNF- $\alpha$ can also affect muscle mass indirectly by its inflammatory properties and consequent joint pain and reduction in physical activity (see vicious circle described above). So, a lack of exercise exacerbates the cytokine driven loss of muscle mass. Resistance training is a major anabolic stimulus, increases muscle strength and physical functioning and should therefore have a direct positive effect on the maintenance of muscle mass. Aerobic training on the other hand, could be especially useful in the 
prevention of long-term complications of cachexia, such as insulin resistance and cardiovascular disease.

Rall et al. studied the effect of 12 weeks of high-intensity progressive resistance training of all major muscle groups in patients with RA. The training was performed twice-weekly and consisted of 3 sets of 8 repetitions of 5 different exercises (chest press, leg press, leg extension, back extension and abdominal curl machines), with the resistance set at $80 \%$ of 1 -repetition maximum. Although there was a significant increase in strength, there was no change in body cell mass (using total body potassium counting) or fat-free mass (using Dual Energy X-ray Absorptiometry, DEXA) [26]. In a more recent study from Marcora et al., patients with RA participated in progressive resistance training, on average 2.5 times a week for 12 weeks. Training was also based on 3 sets of 8 repetitions with a load corresponding to $80 \%$ of 1 -repetition maximum, but they included 8 different exercises. There was a significant increase in fat-free mass, measured by DEXA, which was mainly concentrated in arms and legs [27]. The fact that they did find a positive result on fat-free mass in contradiction to Rall and colleagues is likely attributable to the higher number of resistance exercises per training session and the higher training frequency, since almost all other study characteristics were identical [27]. A study from Hakkinen et al. confirmed the positive effects of training on muscle mass. They found that a 21 week combined strength and endurance training program significantly increased muscle mass in women with RA [28].

Although literature on the effect of exercise on body composition in patients with RA is limited, the described studies indicate that an increase in fat-free mass can be obtained when a sufficient training dose is present. The question then arises whether resistance training, which puts a considerable load on the joints and muscles, has detrimental effects on disease activity.

\section{Exercise and joint damage}

Disease activity measured by inflammatory markers, pain or changes in range of motion are commonly used outcome measures to assess possible unfavourable effects of exercise. An overview of 15 randomised controlled studies assessing these parameters is provided by Stenström and Minor [17]. The conclusion of these studies was that pain and the ability to perform activities of daily life remained unchanged in most studies, and that disease activity was either reduced or unchanged. Even though these parameters provide an indication of disease activity, the ultimate parameter of interest in RA is joint damage. Joint damage progresses with years in nearly every patient due to the fact that 1) once inflamed, joints hardly ever come to a remission and 2) once damaged, joint cartilage and bone wear of more easily. The effect of exercise on radiographic joint damage is scarce, conceivably because exercise interventions need to be sufficiently long in duration in order to assess radiographic progression. Nevertheless, some long-term studies are available, ranging from 26 weeks [29] to several years [30-36]. Only the latter will be discussed here. Nordemar et al. [35] investigated the effectiveness and safety of a supervised, longterm (4-6 years) exercise program performed once every other week compared to usual care. Radiological progression of clini- cally affected joints was less pronounced in the exercise group than in the control group. In a study of Stenström et al. [36] patients with RA performed intensive dynamic water-based exercises once a week and radiographic evaluation was compared with a usual care group. After 4 years, there were no differences in radiological progression between the groups. It has to be noticed however that although exercise intensity in both these trials was sufficiently high, the frequency was low, i.e. once every other week [35] and once a week [36]. Results of other studies investigating the effect of exercise on radiographic progression showed no differences between intervention and control groups [30,33,34,37] or were even slightly in favour of the exercise group [31]. Long-term highintensity exercise in the Rheumatoid Arthritis Patients in Training trial [30] showed no statistically significant differences in radiographic progression of the large joints between the exercise and the control group. A subgroup analysis however showed, that the association between long-term high-intensity weight-bearing exercise and joint damage was influenced by baseline damage [38]. More details of the above mentioned trials can be found in a review by de Jong et al. [39].

It seems from these studies that exercise, even high-intensity exercise, is safe for patients with rheumatoid arthritis. None of them found evidence for more radiographic joint damage with training compared to controls, except in a subgroup of patients who already had extensive baseline damage of large joints [38].

\section{Conclusion}

The consensus of systematic reviews is that patients with rheumatoid arthritis, participating in exercise interventions, demonstrate improved aerobic fitness and muscle strength. As a consequence, patients' ability to perform activities of daily life and health-related quality of life should improve as well, although not all studies have found an effect on these two parameters. It is possible that questionnaires, designed to assess these parameters, such as the Stanford Health Assessment Questionnaire [40] are not sensitive enough to capture exercise effects additional to medication [17]. With regards to pain, disease activity and joint damage, there is no evidence that exercise has detrimental effects on disease activity $[17,18,39]$. Some studies even showed less joint damage in the exercise versus control group. Care should be taken when prescribing exercise in patients with severe baseline joint damage [38] and evidence is lacking for the positive or negative effects of exercise in patients of functional classes III and IV [18]. However, most likely these patients will also benefit from moderate intensity physical activity, that places little stress on the joints. As also applies for the general population, patients will benefit most from an overall increase in physical activity, to improve cardiovascular and muscular fitness, which can be maintained throughout life. Exercise prescriptions are often hard to sustain over longer periods of time, particularly a lifetime. In fact, patients should be encouraged to be as physically active as possible, have a variety of activity options, build activities into their daily routines and develop an active lifestyle, rather than just following exercise prescriptions [41].

So far, some research questions have not been sufficiently addressed. There is no concrete evidence that daily physical 
activity is indeed lower in patients with RA compared to the general population. Secondly, it is unclear how total daily physical activity affects disease activity. Do patients that are sufficiently physically active suffer from less severe disease activity and are they therefore better able to maintain physical functioning. Or are only those patients with a moderate disease activity able to be sufficiently active to maintain functional independency. In addition, there is a lack of literature on the effects of exercise on the rate of cardiovascular events. This should be addressed in future research since the mortality rate in patients with RA is largely caused by cardiovascular death.

There is no doubt, that there is a lot more evidence in favour of prescribing physical activity for patients with RA than there is against. The conclusion is in full agreement with the statement of Nordermar et al. in 1981 [35]: "The risk for a patient of being too inactive is much higher than being too active".

\section{References}

[1] De Carvalho MR, Tebexreni AS, Salles CA, Barros Neto T, Natour J. Oxygen uptake during walking in patients with rheumatoid arthritis-a controlled study. J Rheumatol 2004;31(4):655-62.

[2] Ottawa-Panel. Ottawa Panel evidence-based clinical practice guidelines for therapeutic exercises in the management of rheumatoid arthritis in adults. Phys Ther 2004;84(10):934-72.

[3] Ekdahl C, Broman G. Muscle strength, endurance, and aerobic capacity in rheumatoid arthritis: a comparative study with healthy subjects. Ann Rheum Dis 1992;51(1):35-40.

[4] Wolfe F, Allaire S, Michaud K. The prevalence and incidence of work disability in rheumatoid arthritis, and the effect of anti-tumor necrosis factor on work disability. J Rheumatol 2007;34(11):2211-7.

[5] Walsmith J, Roubenoff R. Cachexia in rheumatoid arthritis. Int J Cardiol 2002;85(1):89-99.

[6] Caspersen CJ, Powell KE, Christenson GM. Physical activity, exercise, and physical fitness: definitions and distinctions for health-related research. Public Health Rep 1985;100(2):126-31.

[7] Meijer EP, Westerterp KR, Verstappen FT. Effect of exercise training on total daily physical activity in elderly humans. Eur J Appl Physiol Occup Physiol 1999;80(1):16-21.

[8] Roubenoff R, Roubenoff RA, Cannon JG, Kehayias JJ, Zhuang H, Dawson-Hughes B, et al. Rheumatoid cachexia: cytokine-driven hypermetabolism accompanying reduced body cell mass in chronic inflammation. J Clin Invest 1994;93(6):2379-86.

[9] Roubenoff R, Roubenoff RA, Ward LM, Holland SM, Hellmann DB. Rheumatoid cachexia: depletion of lean body mass in rheumatoid arthritis. Possible association with tumor necrosis factor. J Rheumatol 1992;19 (10):1505-10.

[10] Mancuso CA, Rincon M, Sayles W, Paget SA. Comparison of energy expenditure from lifestyle physical activities between patients with rheumatoid arthritis and healthy controls. Arthritis Rheum 2007;57 (4):672-8.

[11] Wikstrom I, Book C, Jacobsson LT. Difficulties in performing leisure activities among persons with newly diagnosed rheumatoid arthritis: A prospective, controlled study. Rheumatol (Oxf) 2006;45(9):1162-6.

[12] Lemmey A, Maddison P, Breslin A, Cassar P, Hasso N, McCann R, et al. Association between insulin-like growth factor status and physical activity levels in rheumatoid arthritis. J Rheumatol 2001;28(1):29-34.

[13] Solomon DH, Curhan GC, Rimm EB, Cannuscio CC, Karlson EW. Cardiovascular risk factors in women with and without rheumatoid arthritis. Arthritis Rheum 2004;50(11):3444-9.

[14] Roubenoff R, Walsmith J, Lundgren N, Snydman L, Dolnikowski GJ, Roberts S. Low physical activity reduces total energy expenditure in women with rheumatoid arthritis: implications for dietary intake recommendations. Am J Clin Nutr 2002;76(4):774-9.
[15] Black AE, Coward WA, Cole TJ, Prentice AM. Human energy expenditure in affluent societies: an analysis of 574 doubly-labelled water measurements. Eur J Clin Nutr 1996;50(2):72-92.

[16] Henderson CJ, Lovell DJ, Specker BL, Campaigne BN. Physical activity in children with juvenile rheumatoid arthritis: quantification and evaluation. Arthritis Care Res 1995;8(2):114-9.

[17] Stenstrom CH, Minor MA. Evidence for the benefit of aerobic and strengthening exercise in rheumatoid arthritis. Arthritis Rheum 2003;49(3): 428-34.

[18] Pedersen BK, Saltin B. Evidence for prescribing exercise as therapy in chronic disease. Scand J Med Sci Sports 2006;16(Suppl 1):3-63.

[19] Hakkinen A, Hannonen P, Hakkinen K. Muscle strength in healthy people and in patients suffering from recent-onset inflammatory arthritis. Br J Rheumatol 1995;34(4):355-60.

[20] Jenkins A, Plasqui G. Exercise and disorders of metabolism., in Physiological Bases of Human Performance during Work and Exercise, N.A.S. Taylor, H. Groeller, and P.L. McLennan, Editors. in press., Churchill Livingstone (Elsevier Limited): Oxford, England.

[21] Rall LC, Roubenoff R. Rheumatoid cachexia: metabolic abnormalities, mechanisms and interventions. Rheumatol (Oxf) 2004;43(10):1219-23.

[22] Henderson C, Davis JC. Drug insight: anti-tumor-necrosis-factor therapy for ankylosing spondylitis. Nat Clin Pract Rheumatol 2006;2(4):211-8.

[23] Walsmith J, Abad L, Kehayias J, Roubenoff R. Tumor necrosis factoralpha production is associated with less body cell mass in women with rheumatoid arthritis. J Rheumatol 2004;31(1):23-9.

[24] Guttridge DC, Mayo MW, Madrid LV, Wang CY, Baldwin Jr AS. NF-kappaBinduced loss of MyoD messenger RNA: possible role in muscle decay and cachexia. Science 2000;289(5488):2363-6.

[25] Marcora SM, Chester KR, Mittal G, Lemmey AB, Maddison PJ. Randomized phase 2 trial of anti-tumor necrosis factor therapy for cachexia in patients with early rheumatoid arthritis. Am J Clin Nutr 2006;84(6):1463-72.

[26] Rall LC, Meydani SN, Kehayias JJ, Dawson-Hughes B, Roubenoff R. The effect of progressive resistance training in rheumatoid arthritis. Increased strength without changes in energy balance or body composition. Arthritis Rheum 1996;39(3):415-26.

[27] Marcora SM, Lemmey AB, Maddison PJ. Can progressive resistance training reverse cachexia in patients with rheumatoid arthritis? Results of a pilot study. J Rheumatol 2005;32(6):1031-9.

[28] Hakkinen A, Pakarinen A, Hannonen P, Kautiainen H, Nyman K, Kraemer $\mathrm{WJ}$, et al. Effects of prolonged combined strength and endurance training on physical fitness, body composition and serum hormones in women with rheumatoid arthritis and in healthy controls. Clin Exp Rheumatol 2005;23 (4):505-12.

[29] Hakkinen A, Hakkinen K, Hannonen P. Effects of strength training on neuromuscular function and disease activity in patients with recent-onset inflammatory arthritis. Scand J Rheumatol 1994;23(5):237-42.

[30] de Jong Z, Munneke M, Zwinderman AH, Kroon HM, Jansen A, Ronday $\mathrm{KH}$, et al. Is a long-term high-intensity exercise program effective and safe in patients with rheumatoid arthritis? Results of a randomized controlled trial. Arthritis Rheum 2003;48(9):2415-24.

[31] de Jong Z, Munneke M, Zwinderman AH, Kroon HM, Ronday KH, Lems $\mathrm{WF}$, et al. Long term high intensity exercise and damage of small joints in rheumatoid arthritis. Ann Rheum Dis 2004;63(11):1399-405.

[32] Hakkinen A, Sokka T, Kautiainen H, Kotaniemi A, Hannonen P. Sustained maintenance of exercise induced muscle strength gains and normal bone mineral density in patients with early rheumatoid arthritis: a 5 year follow up. Ann Rheum Dis 2004;63(8): 910-6.

[33] Hakkinen A, Sokka T, Kotaniemi A, Hannonen P. A randomized two-year study of the effects of dynamic strength training on muscle strength, disease activity, functional capacity, and bone mineral density in early rheumatoid arthritis. Arthritis Rheum 2001;44(3):515-22.

[34] Hansen TM, Hansen G, Langgaard AM, Rasmussen JO. Longterm physical training in rheumatoid arthritis. A randomized trial with different training programs and blinded observers. Scand J Rheumatol 1993;22(3):107-12.

[35] Nordemar R, Ekblom B, Zachrisson L, Lundqvist K. Physical training in rheumatoid arthritis: a controlled long-term study. I. Scand J Rheumatol 1981;10(1):17-23. 
[36] Stenstrom CH, Lindell B, Swanberg E, Swanberg P, Harms-Ringdahl K, Nordemar R. Intensive dynamic training in water for rheumatoid arthritis functional class II-a long-term study of effects. Scand J Rheumatol 1991;20(5):358-65.

[37] Hakkinen A, Sokka T, Hannonen P. A home-based two-year strength training period in early rheumatoid arthritis led to good long-term compliance: a five-year followup. Arthritis Rheum 2004;51(1):56-62.

[38] Munneke M, de Jong Z, Zwinderman AH, Ronday HK, van Schaardenburg D, Dijkmans BA, et al. Effect of a high-intensity weight-bearing exercise program on radiologic damage progression of the large joints in subgroups of patients with rheumatoid arthritis. Arthritis Rheum 2005;53 (3):410-7.

[39] de Jong Z, Vlieland TP. Safety of exercise in patients with rheumatoid arthritis. Curr Opin Rheumatol 2005;17(2):177-82.

[40] Fries JF, Spitz P, Kraines RG, Holman HR. Measurement of patient outcome in arthritis. Arthritis Rheum 1980;23(2):137-45.

[41] Finckh A, Iversen M, Liang MH. The exercise prescription in rheumatoid arthritis: primum non nocere. Arthritis Rheum 2003;48(9):2393-5. 